\title{
Study on mechanical properties of titanium alloy drill pipe and application technology
}

\author{
Yang Xiaoyong ${ }^{1}$, Chen Shichun ${ }^{1}$, Feng Qiang ${ }^{1}$, Zhang Wenhua ${ }^{1}$, Wang Yue ${ }^{1}$ \\ ${ }^{1}$ Engineering Technology Research Institute, BHDC, Tianjin 300280, China
}

\begin{abstract}
With the increasing intensity of oil and gas field exploration and development, oil and gas wells are also drilling into deeper and more complex formations. Conventional steel drilling tools can no longer meet the requirements of ultra-deep, high-temperature and high-pressure wells. The paper first analyzes the advantages of titanium alloy drill pipe based on basic performance of titanium alloy drill pipe. The experimental results show that the basic properties of titanium alloy drill pipes meet the operating standards of the petroleum industry. Then the buckling performance of titanium alloy drill pipe and steel drill pipe is compared, the calculation results show that the buckling performance of titanium alloy drill tools is slightly lower than that of steel drill tools. Secondly, the maximum allowable buildup rate of titanium alloy drill pipe and steel drill tool is studied. The research shows that under the same condition of the drill pipe outer diameter, titanium alloy drill pipe can be used for a smaller curvature radius and greater buildup rate. This advantage of titanium alloy drill pipe makes it more suitable for short radius and ultra-short radius wells. Finally, taking a shale gas horizontal well as an example, with the goal of reducing drill string friction and ensuring drill string stability, a comparative study on the application of titanium alloy drill pipe and steel drill pipe is carried out. The results show that titanium alloy drill pipe has a wider application in the field, and is suitable for operations under various complex working conditions.
\end{abstract}

\section{Introduction}

Oil and gas field development is faced with the dual pressures of enhancing oil recovery and improving quality and efficiency, and there are more and more complex wells. Factors such as the inclination angle of the wellbore of extended reach, the size of annulus and drill string, the eccentricity of drill pipe, and other factors have resulted in the complex wellbore trajectory. It is difficult to control the distribution of friction and torque and to stabilize the deviation of rotary steering drilling. High temperature and high pressure have strict requirements on drilling tools, downhole tools and instruments [1]. The deviation section of short radius horizontal well is short, the inclination rate is high, the wellbore is irregular, and the drill string "self-locking" is easy to occur [2]. High pump pressure, high friction resistance, prominent supporting pressure phenomenon and difficult drilling pressure transmission is common in windowed sidetracking horizontal wells [3]. In the face of the above problems, the alternating stress generated by ordinary drill pipe construction is very large, which often causes fatigue fracture of the drill pipe. Therefore, domestic and foreign scholars try to develop titanium alloy drill pipe to replace ordinary drill pipes. Titanium alloy drill pipes were first developed by Grant Prideco and RTI Energy Systems at the beginning of this century [4-6]. Titanium alloys have high toughness. Therefore, it is often used in drilling operations with small radius of curvature [7]. Researchers have successfully used titanium alloy drill pipes in oil well operations in Colorado, USA, and achieved the purpose of sidetracking with short curvature radius [8]. At present, $110 \mathrm{ksi}$ grade titanium alloy drill pipes have been produced in China. The drill pipes are independently developed by Bohai Nengke Company [9]. Compared with conventional ordinary steel S135 drill pipes, its advantages are as follows:

(1) Extend the displacement of extended reach wells and horizontal wells

The density of titanium alloy is only $4.5 \mathrm{~g} / \mathrm{cm} 3$, and the floating weight of drill pipe with the same wall thickness and length in the horizontal section drilling fluid with a conventional density of $1.25 \mathrm{~g} / \mathrm{cm} 3$ is only $49 \%$ of that of steel drill pipe [10]. In this case, the friction resistance is only about $50 \%$ of the ordinary drill pipe, and the friction torque of the pipe string is one of the core problems of extended reach technology, which determines the maximum extension of horizontal displacement, so titanium alloy drill pipe can be more conducive to extended reach wells and three-dimensional cluster horizontal wells [11]. At present, in more and more cases of industrial drilling in China, titanium alloy drill pipe is used more widely.

(2) Reduce ground equipment load

Titanium alloy drill pipe is light in weight, resulting in a torque reduction of nearly $50 \%$, which effectively reduces the load of the top drive (turntable) on the

* Corresponding author: 1013607120@qq.com 
ground, greatly reduces the probability of damage and diesel consumption [12].

(3) Reduce the hydraulic loss of the joint

Titanium alloy drill pipe is light in weight and low in torque. The processed drill pipe joints do not need to be as strengthened as steel drill pipes. Generally, when using $\varphi 127 \mathrm{~mm} \mathrm{S135}$ drill pipes in horizontal wells, the joint inner diameter is reduced from $\phi 82.55 \mathrm{~mm}$ of G105 drill pipes to $\phi 69.85 \mathrm{~mm}$, due to the reduced torque, 80 ksi titanium alloy drill pipe can reach the strength of S135 steel grade at the same displacement (because the floating weight is reduced by $51 \%$, the torque will also be reduced by 51\%) [13]. The inner diameter of X95 steel grade drill pipe joints reaches $\phi 88.9 \mathrm{~mm}$. The increase in the inner diameter of the joint can significantly reduce circulating pressure loss.

\section{Basic performance test of titanium alloy drill pipe}

\subsection{Hardness testing}

The Brinell hardness tester was used to test the HRC hardness, rigid body hardness and weld zone profile hardness of titanium alloy material joints [14]. The test results are shown in Table 1.

Table 1. Hardness test results of different positions of titanium alloy materials

\begin{tabular}{ccccc}
\hline \multirow{2}{*}{ Location } & \multicolumn{4}{c}{ Hardness (HRC) } \\
\cline { 2 - 5 } & 1 & 2 & 3 & average \\
Tube & 32.2 & 28.4 & 30.2 & 30.3 \\
Joint & 34.0 & 35.1 & 34.3 & 34.5 \\
Welding & 30.3 & 30.5 & 30.4 & 30.4 \\
\hline
\end{tabular}

The test results show that the average hardness (HRC) of the titanium alloy pipe body is 34.5 , which is greater than the average hardness (HRC) of the titanium alloy joint of 30.3. The average hardness of the titanium alloy weld zone profile (HRC) is 30.4 , and there is no obvious fluctuation point. The hardness of titanium alloy is basically equivalent to that of steel drill pipe. The hardness test results show that the hardness of the material is evenly distributed. Friction welding and postweld heat treatment can meet the requirements of titanium alloy drill pipe manufacturing.

\subsection{Tensile performance test}

In tensile performance test, TC4U titanium alloy is used, in accordance with GB/T228-2002 "Metallic Material Tensile Test Method at Room Temperature" [15].

Test principle: The test is generally carried out in the room temperature range of $10^{\circ} \mathrm{C}-35^{\circ} \mathrm{C}$. The test system uses tensile force to stretch the sample, and generally pulls to break to determine the tensile properties of the material.

The accuracy requirement of the measurement: The minimum original cross-sectional area (So) is required to be measured. Calculate the original cross-sectional area of the sample with the measured cross-sectional dimensions. Unless otherwise specified in the relevant product standard or agreement, the nominal crosssectional area is not used.

The tensile testing machine of the State Key Laboratory of Southwest Petroleum University is shown in figure 1 , and the tensile samples are shown in figure 2.

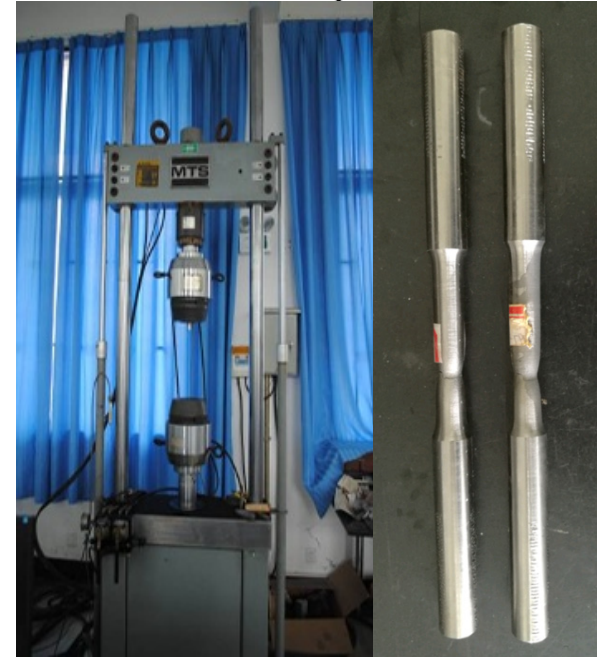

Fig. 1. Tensile testing machine.

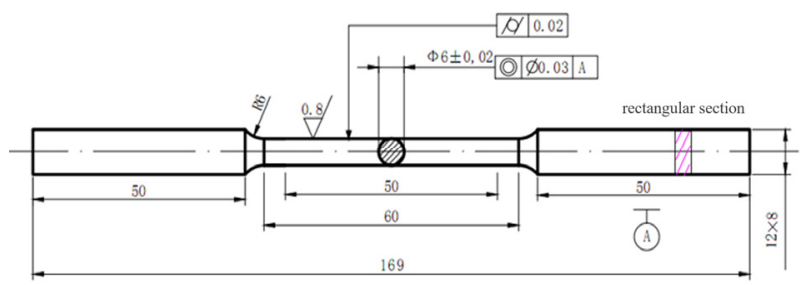

Fig. 2. Circular cross-section specimen.

Measuring position and method are as follows:

(1) For the sample with circular cross-sectional area, the diameter is measured in two directions perpendicular to each other on the two ends. The average diameter is taken to calculate the area, and the minimum value measured in three places is the original cross-sectional area of the sample.

(2) For rectangular and arc-shaped cross-sectional samples, the thickness (or wall thickness) and width are measured at both ends. The minimum cross-sectional area measured at the three places is the original crosssectional area of the sample.

(3) For the annular cross-section specimen (circular tube section sample), the outer diameter and wall thicknesses are measured in the direction perpendicular to each other at one end. The cross-sectional area calculated by the average outer diameter and average wall thickness is the original cross-sectional area of the sample.

The results of the tensile test at different positions of the titanium alloy material are shown in Table 2 . The test data shows that the tensile and yield strength of the pipe body is the strongest, and the elongation at the weld is the highest. 
Table 2. Tensile test results at different positions of titanium alloy materials.

\begin{tabular}{ccccc}
\hline \multirow{2}{*}{ Sampling location } & Status & $\begin{array}{c}\text { Tensile test } \\
\text { (MPa) }\end{array}$ & $\begin{array}{c}\text { Yield Strength } \\
(\mathrm{MPa})\end{array}$ & Elongation (\%) \\
\cline { 3 - 5 } Pipe body & After heat treatment & 1019 & 929 & 12.44 \\
Pipe body & After heat treatment & 1015 & 926 & 10.42 \\
Joint & After heat treatment & 943 & 846 & 15.76 \\
Joint & After heat treatment & 945 & 853 & 14.28 \\
Weld & After heat treatment & 951 & 845 & 14.60 \\
Weld & After heat treatment & 946 & 842 & 15.28 \\
\hline
\end{tabular}

Through tensile tests on the titanium alloy pipe body and joints, the experiment shows that the joint strength is basically matched with pipe body. The yield strength after heat treatment of weld are equivalent to $91 \%$ of pipe body, and the weld has good performance.

\section{Buckling Performance Study}

In ultra-deep wells, drilling tools are in a complex stress state with periodic changes for a long time due to the influence of wellbore temperature and pressure. The drill string will buckle and deform in the wellbore. When the axial compression load of drill pipe reaches a certain critical value, the linear equilibrium state of drill pipe is no longer stable. A small increase of load will cause pipe string to buckle into a sinusoidal shape. At this time, drill pipe will undergo two-dimensional sinusoidal buckling. After drill pipe undergoes sinusoidal buckling, the continued increase in load will aggravate the lateral deformation of the buckling configuration of drill pipe. Once the load reaches another critical value, the buckling configuration of drill pipe will become a threedimensional helical shape and maintain continuous contact with inner wall of borehole [16]. The critical loads of sinusoidal buckling and helical buckling in different well sections are shown in Table 3 .

Table 3. Critical loads of sinusoidal and helical buckling for different well sections.

\begin{tabular}{ccc}
\hline Well section & Sinusoidal buckling critical load & Helical buckling critical load \\
\hline $\begin{array}{c}\text { Vertical well } \\
\text { section } \\
\begin{array}{c}\text { Inclined well } \\
\text { section }\end{array}\end{array}$ & $F_{\text {sin }}=2.55 * \sqrt[3]{E L q^{2}}$ & $F_{h e l}=5.55 * \sqrt[3]{E L q^{2}}$ \\
Curved section & $F_{\text {sin }}=2 \sqrt{E L q \sin \alpha / r}$ & $F_{\text {sin }}=4 \sqrt{2 E I q \sin \alpha / r}$ \\
$\begin{array}{c}\text { Horizontal well } \\
\text { section }\end{array}$ & $F_{\sigma}=\frac{2 E I}{r R}\left(1+\sqrt{1+\frac{q r R^{2} \sin \alpha}{E I}}\right)$ & $F_{\sigma}=\frac{8 E I}{r R}\left(1+\sqrt{1+\frac{q r R^{2} \sin \alpha}{2 E I}}\right)$ \\
& $F_{\text {sin }}=2 \sqrt{E I q / r}$ & $F_{\text {sin }}=4 \sqrt{E I q / r}$
\end{tabular}

According to the formula in the above table, we have compared the critical load of helical buckling for steel

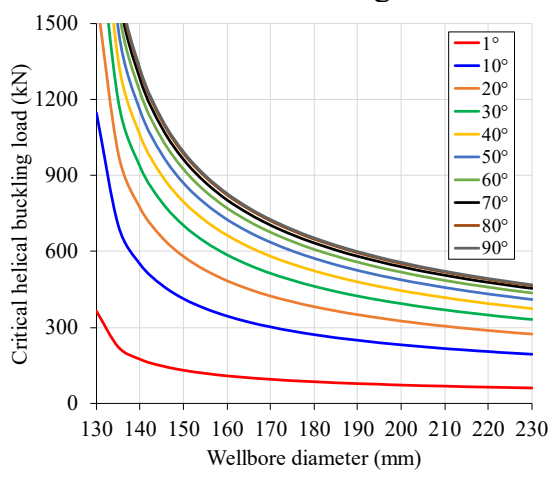

(a) Steel drill pipe drilling tools and titanium alloy drilling tools at different inclination angles and different borehole diameters. The comparison results are shown in figure 3 .

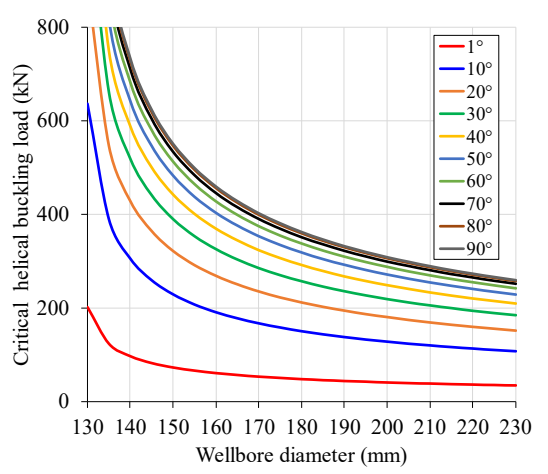

(b) Titanium alloy drill pipe

Fig. 3. Comparison of helical buckling critical load in the inclined well section.

It can be seen from figure 3 that as the borehole diameter increases, the critical buckling load of drill pipe gradually decreases, that is, drill pipe is more likely to buckle in a large-diameter wellbore. When the borehole diameter is small, the effect of wellbore diameter is significant. As the borehole diameter further increases, the critical buckling load of drill pipe does not change much. As the inclination angle increases, the critical buckling load of drill pipe under the same borehole diameter gradually increases. This shows that gravity plays a certain role in promoting the buckling of drill pipe. As the inclination angle increases, the component of gravity in the direction of the borehole axis gradually decreases. Under the same wellbore diameter and 
inclination angle, the critical buckling load of titanium alloy drill pipe is lower than that of steel drill pipe, indicating that titanium alloy drill pipe is more prone to buckling than steel drill pipe under the same load.

According to the calculation formula for the critical buckling load of in the curved section, the critical buckling load of the titanium alloy drill pipe and steel drill pipe in curved section is calculated, as shown in figure 4 .

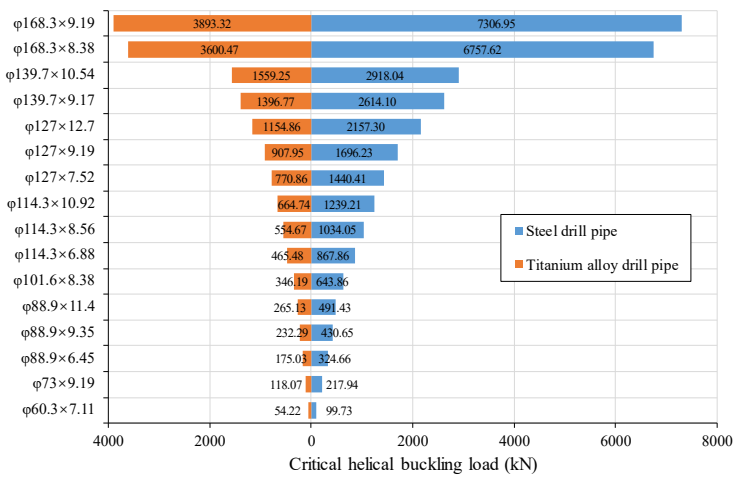

Fig. 4. Comparison of critical load of helical buckling in curved well section.

It can be seen from figure 4 that the critical buckling load of titanium alloy drill pipes is $53.3 \%$ to $54.4 \%$ of that of conventional steel drill pipes in curved well sections, indicating that under the same load, titanium alloy drill pipes are more prone to buckling than steel drill pipes.

\section{Maximum allowable buildup rate study}

The calculation formula for the bending normal stress of the drill pipe in curved wellbore is expressed as:

$$
\sigma=\frac{D E}{2 R}
$$

Therefore, the calculation formula for the minimum allowable borehole curvature radius based on the rotary fatigue life of drill pipe is expressed as:

$$
R_{\min }=\frac{D E}{2 \sigma_{f}}
$$

Then the maximum allowable build-up rate of drill pipe is:

$$
k_{\max }=\frac{180}{\pi} \frac{30}{R_{\max }}=\frac{10800 \sigma_{f}}{\pi D E}
$$

where, $\sigma$ is the bending normal stress, $\mathrm{MPa} ; D$ is the drill pipe outer diameter, $\mathrm{m} ; E$ is the modulus of elasticity, $\mathrm{MPa} ; R$ is the radius of curvature of the borehole, $\mathrm{m}$; of is the constant stress level with $10^{7}$ rotation fatigue life, or it is called the fatigue limit, $\mathrm{MPa} ; R_{\min }$ is the minimum allowable curvature radius of the wellbore, $\mathrm{m} ; k_{\max }$ is the maximum allowable buildup rate, ${ }^{\circ} / 30 \mathrm{~m}$.

If the safety factor is considered as $S_{f}$, the minimum allowable borehole curvature radius and the maximum allowable build-up rate of drill pipe are expressed as:

$$
\begin{gathered}
R_{\min }^{\prime}=\frac{D E}{2 \sigma_{f}} \cdot S_{f} \\
k_{\max }=\frac{180}{\pi} \frac{30}{R_{\min }^{\prime}}=\frac{10800 \sigma_{f}}{\pi D E \cdot S_{f}}
\end{gathered}
$$

The comparison of the minimum allowable borehole curvature radius and the maximum allowable deflection rate of titanium alloy drill pipe, S135 steel drill pipe and G105 steel drill pipe are shown in figure 5 and figure 6, respectively.

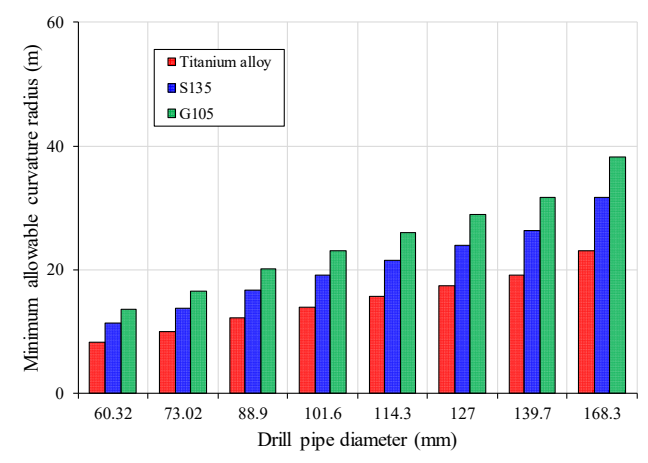

Fig. 5. Comparison of the minimum allowable borehole curvature radius.

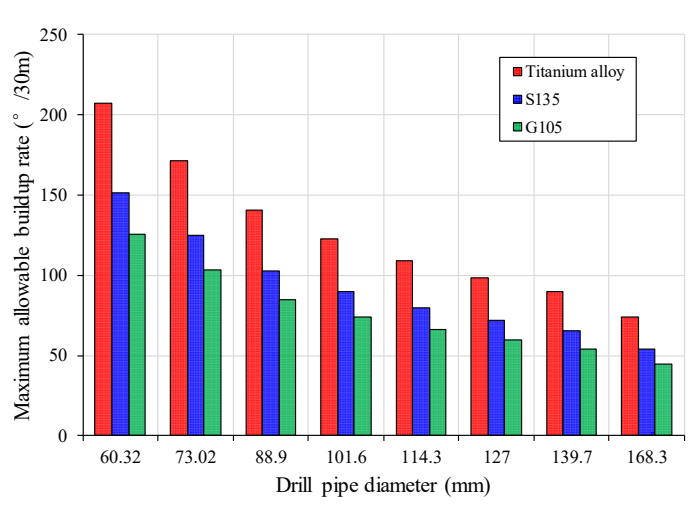

Fig. 6. Comparison of the maximum allowable buildup rate.

As can be seen from figure 5 and figure 6 , under the condition of the same outer diameter of drill pipe, titanium alloy drill pipe can be used for smaller wellbore curvature radius and larger buildup rate than S135 steel drill pipe and G105 steel drill pipe. This advantage of titanium alloy drill pipe makes it more suitable for short radius and ultra-short radius wells.

\section{Application of titanium alloy drill pipe}

In order to compare the performance of titanium alloy drill pipes and steel drill pipes in directional wells, a shale gas horizontal well is taken as an example. Aiming at reducing drill string friction and ensuring drill string stability, a comparative study on the application of titanium alloy drill pipe and steel drill pipe under different working conditions is carried out.

The designed borehole trajectory of this well is shown in figure 7 . The well is a typical threedimensional horizontal well. Generally, the borehole 
trajectory profile of "straight-increasing-stabilizationincreasing (torsion)-stability-increasing (torsion)horizontal section" is adopted, The deflection point is

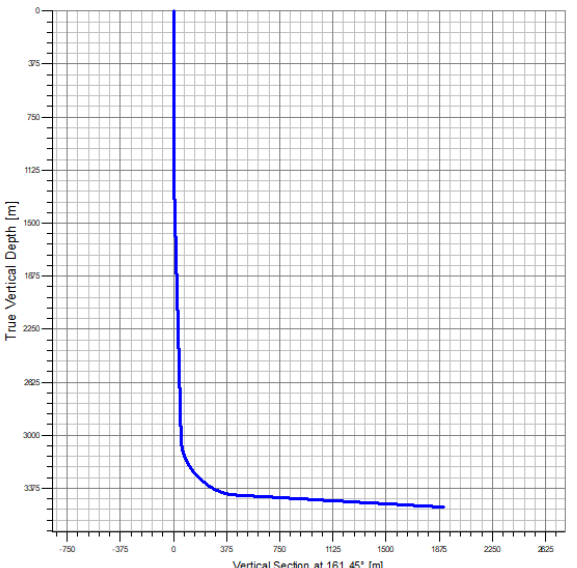

(a) Vertical projection
$3090 \mathrm{~m}$ deep, horizontal displacement is $1900 \mathrm{~m}$, and the maximum deviation angle is $86.76^{\circ}$.

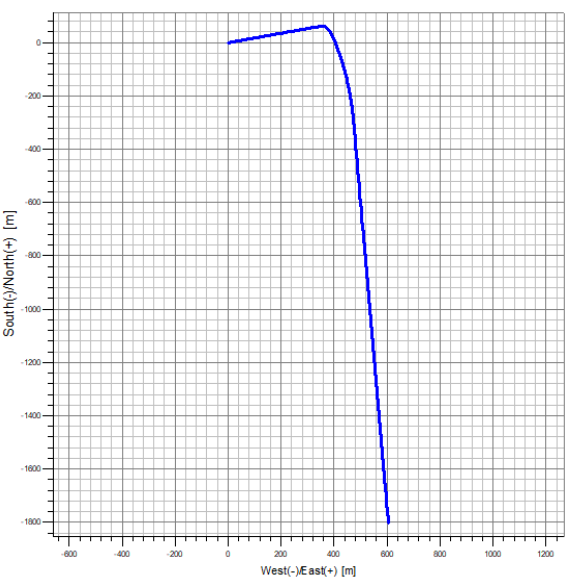

(b) Horizontal projection

Fig. 7. Schematic diagram of designed well trajectory.

Comparing the performance of titanium alloy drill pipe and steel drill pipe under the original design well trajectory, the two drill string combinations are as follows:

Steel drill pipe combination: $\Phi 215.9 \mathrm{~mm}$ PDC drill bit $+\Phi 172 \mathrm{~mm} 1.5^{\circ}$ single-bending screw $+\Phi 212 \mathrm{~mm}$ ball support + float valve + MWD + $\Phi 139.7 \mathrm{~mm}$ nonmagnetic pressure-bearing drill pipe $+\Phi 127 \mathrm{~mm}$ heavy drill pipe $3+$ jar $+\Phi 127 \mathrm{~mm}$ weighted drill pipe 3 pieces $+\Phi 127 \mathrm{~mm}$ drill pipe 9 pieces $+\Phi 165.1 \mathrm{~mm}$ hydraulic oscillator $+\Phi 127 \mathrm{~mm}$ drill pipe $+\Phi 127 \mathrm{~mm}$ weighted drill pipe $\times 50$ pieces $+\Phi 139.7 \mathrm{~mm}$ drill pipe $\times 293 \mathrm{~m}$.

Titanium alloy drill pipe assembly (titanium alloy drill pipe is used below the deflection point): $\Phi 215.9 \mathrm{~mm}$ PDC drill bit $+\Phi 172 \mathrm{~mm} 1.5^{\circ}$ single bend screw + $\Phi 212 \mathrm{~mm}$ ball support + float valve + MWD + $\Phi 139.7 \mathrm{~mm}$ non-magnetic pressure drill Rod $+\Phi 127 \mathrm{~mm}$ weighted drill pipe 3 pieces + jar $+\Phi 127 \mathrm{~mm}$ weighted drill pipe 3 pieces $+\Phi 127 \mathrm{~mm}$ drill pipe 9 pieces + $\Phi 165.1 \mathrm{~mm}$ hydraulic oscillator $+\Phi 127 \mathrm{~mm}$ titanium alloy drill pipe $+\Phi 127 \mathrm{~mm}$ weighted drill pipe $\times 50$ pieces $+\Phi 139.7 \mathrm{~mm}$ Drill pipe $\times 293 \mathrm{~m}$.

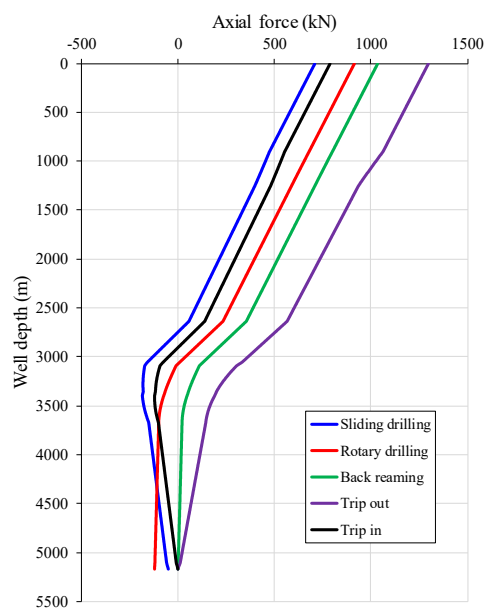

(a) Steel drill pipe assembly
Calculation conditions: open-hole friction coefficient 0.32 , casing friction coefficient 0.21 , drilling fluid density $2.0 \mathrm{~g} / \mathrm{cm}^{3}$, sliding drilling weight-on-bit $50 \mathrm{kN}$, rotary drilling weight-on-bit $120 \mathrm{kN}$, rotation speed 90rpm.

Figure 8 shows the axial force distribution of the two drill string combinations under different working conditions. As can be seen from the figure, wellhead load of trip out condition is the largest, while the wellhead load of sliding drilling condition is the smallest. The density of titanium alloy is lower than that of steel, but because the titanium alloy drill pipe is used in the horizontal section, the reduction of wellhead load is not significant. Through the axial force distribution of drill string in Figure 8 combined with the formula for calculating the buckling critical load of drill pipe, we can judge whether the whole drill string buckles, which well sections buckle and what form of buckling occurs. Under the original wellbore trajectory, there is no buckling of the two kinds of drill string combinations.

Fig. 8. Axial force distribution of drill string. 
The lateral force distribution of the two drill string combinations under different working conditions is shown in figure 9. As can be seen from the figure, when the drill string is in contact with the borehole wall in curved section, the lateral force is greater. Compared

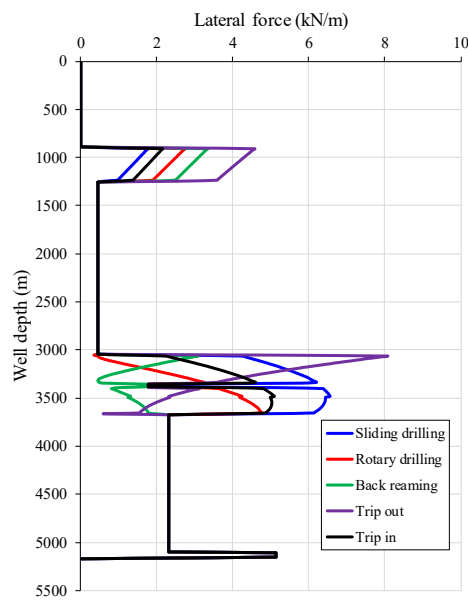

(a) Steel drill pipe assembly with steel drill pipe, titanium alloy drill pipe has lower density and lower elastic modulus, so in curved section, the lateral contact force between titanium alloy drill pipe and borehole wall is lower.

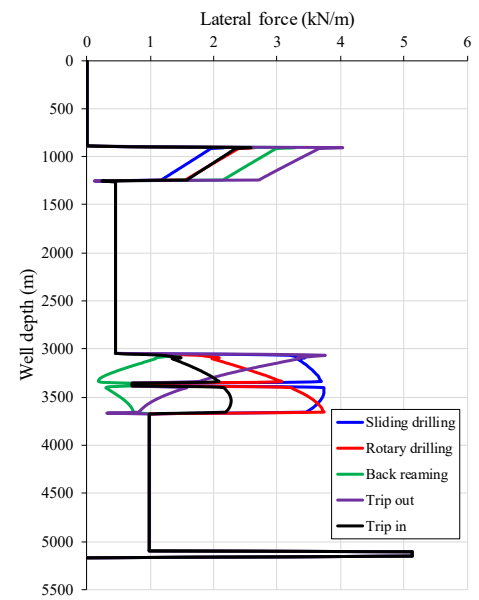

(b) Titanium alloy drill pipe assembly

Fig. 9. Lateral force distribution of drill string.

Figure 10 shows the hook load distribution at different depth. As can be seen from the figure, when steel drill pipe is lowered to a depth below $3500 \mathrm{~m}$, the hook load decreases, and there is a risk of difficulty in lowering. While with the increase of the lowering depth, the large hook load of the titanium alloy drill pipe combination increases gradually, and there is no risk of difficulty in lowering.
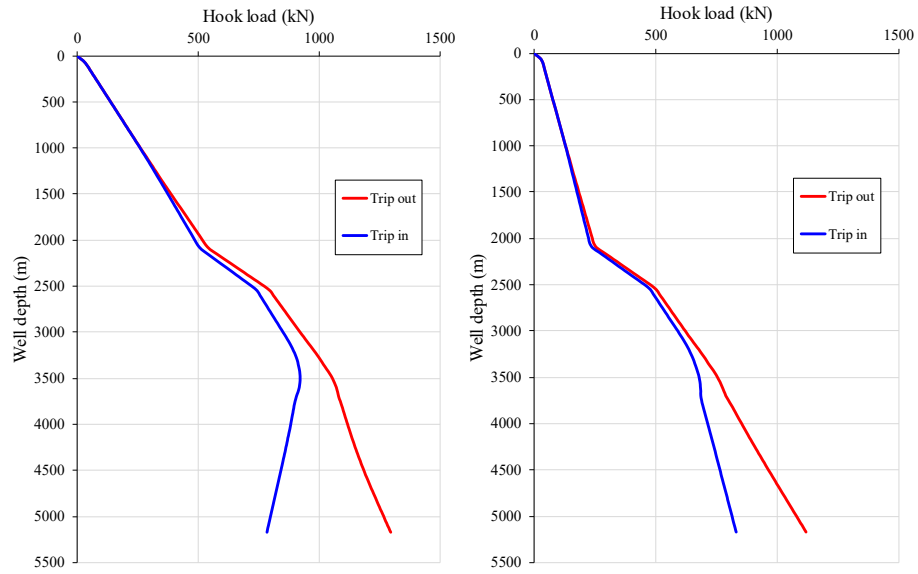

(a) Steel drill pipe assembly (b) Titanium alloy drill pipe assembly

Fig. 10. Hook load distribution at different depth.

Under the original well trajectory, the comprehensive comparison of titanium alloy drill pipe assembly and steel drill pipe assembly is shown in Table 4.

Table 4. Comparison of titanium alloy drill pipe and steel drill pipe

\begin{tabular}{ccccc}
\hline \multirow{2}{*}{ Working condition } & \multicolumn{2}{c}{ Steel drill pipe assembly } & \multicolumn{2}{c}{ Titanium alloy drill pipe assembly } \\
\cline { 2 - 5 } & $\begin{array}{c}\text { Maximum axial } \\
\text { force }(\mathrm{kN})\end{array}$ & $\begin{array}{c}\text { Maximum lateral } \\
\text { force }(\mathrm{kN} / \mathrm{m})\end{array}$ & $\begin{array}{c}\text { Maximum axial } \\
\text { force }(\mathrm{kN})\end{array}$ & $\begin{array}{c}\text { Maximum lateral } \\
\text { force }(\mathrm{kN} / \mathrm{m})\end{array}$ \\
Sliding drilling & 708.2 & 6.6 & 753.1 & 3.8 \\
Rotary drilling & 914.3 & 4.8 & 851.2 & 3.7 \\
Uplift & 1295.1 & 8.1 & 1119.9 & 4 \\
Decentralized & 786.5 & 5.1 & 831.3 & 5.1 \\
\hline
\end{tabular}




\section{Conclusion}

1. Mechanical test shows that the hardness of titanium alloy drill pipe joint and pipe body is high, which is close to that of steel drill pipe. The tensile and yield strength of the pipe body is the strongest, and the elongation at weld is the highest.

2. The calculation models of sinusoidal buckling and helical buckling critical load of titanium alloy drill pipe in vertical, inclined, curved and horizontal sections are established, which provides a basis for judging the buckling state of titanium alloy drill pipe. The critical buckling load of titanium alloy drill pipe and steel drill pipe in different well sections is compared. The critical buckling load of titanium alloy drill pipe is about $50 \%$ of that of steel drill pipe, indicating that under the same load, titanium alloy drill pipe is more prone to buckling than steel drill pipe.

3. A calculation model for the minimum allowable borehole curvature radius and the maximum allowable buildup rate of titanium alloy drill pipes is established, and the maximum allowable buildup rate of titanium alloy drill pipes with different sizes is calculated. Under the condition of the same outer diameter of the drill pipe, titanium alloy drill pipes can be used with a smaller curvature radius and greater buildup rate, this advantage of titanium alloy drill pipe makes it more suitable for short radius and ultra-short radius wells.

4. Compared with the application of titanium alloy drill pipe and steel drill pipe in the field, titanium alloy drill pipe has a wider application in the field compared with steel drill pipe, and it can be applied to various complex working conditions.

\section{References}

1. J. Zhang, W. Xie. Status of Scientific Drilling Technology for Ultra-Deep Well. Acta Geologica Sinica, 84, 887-894 (2010).

2. H. Wang, X. Zheng. Status quo and faced challenges of deep well drilling technique of PetroChina. Petroleum Drilling and Production Technology, 27, 4-8 (2005).

3. Y. Zha, S. Hu, L. Zhuo, et al. Research on the application prospects of Titanium alloy petroleum pipes. Drilling Technology, 40, 1-3 (2017).

4. R. Schutz, H. Warkins. Recent developments in titanium alloy application in the energy industry. Materials Science and Engineering: A, 243, 305-315 (1998).

5. R. Snyder. Titanium Drill Pipe. World Oil, 220, 23 (1999).

6. J. Smith, R. Chandler, P. Boster. Titanium drill pipe for ultra-deep and deep directional drilling. SPE/IADC Drilling Conference. Society of Petroleum Engineering, (2001).

7. S. Waqar, S. Asad, S. Ahmad, et al. Effect of Drilling parameters on hole quality of Ti-6AL-4V
Titanium Alloy in Dry Drilling. Materials Science Forum. Trans Tech Publications, 880, 33-36 (2017).

8. P. Zhao, The latest development of domestic and foreign drill pipe technology. World Steel, 8, 22-27 (2008).

9. W. Yuan, Q. Zhang. Research progress of titanium alloy drill pipes abroad. Xinjiang Petroleum Science and Technology, 16, 13-15 (2006).

10. Y. Wang, C. Zhang, B. Zhang. Safety analysis of new type of titanium alloy and aluminum alloy drill pipe structure. Petroleum Field Machinery, 12, 3133 (2010).

11. Q. Zhao, W. Zhao. Titanium alloy drill pipe for short radius drilling. Petroleum Machinery, 29, 5456 (2001).

12. Z. Shen, H. Huang, D. Gao. New progress and development trend analysis of world drilling technology. Journal of China University of Petroleum (Edition of Natural Science), 4, 64-70 (2009).

13. B. Wang. Research on manufacturing technology of high-strength drill pipe. Xi'an University of Science and Technology, (2014).

14. GB/T 231.1-2009. Brinell hardness test of metallic materials. Part 1: Test method, (2009).

15. GB/T 228-2002, Tensile test method for metal materials at room temperature, (2002).

16. Z. Lian, S. Xu. Analysis of injection and production parameters of gas injection reservoir and critical buckling load of pipe string. Petroleum Drilling and Production Technology, 40, 131-136 (2018). 